\title{
Dynamics of a small surge-type glacier using one-dimensional geophysical inversion
}

\author{
Laetitia DE PAOLI, Gwenn E. FLOWERS
}

Department of Earth Sciences, Simon Fraser University, 8888 University Drive, Burnaby, British Columbia V5A 1S6, Canada
E-mail: gflowers@sfu.ca

\begin{abstract}
We investigate the dynamics of a small surge-type valley glacier as part of a study to characterize glacier response to climate in the Donjek Range, southwest Yukon, Canada. Pole displacements were measured using kinematic GPS techniques during three consecutive summer field seasons. Measured surface velocities range from $<10 \mathrm{ma}^{-1}$ over the lower $1500 \mathrm{~m}$ of the $5 \mathrm{~km}$ long glacier to a maximum of $\sim 25-35 \mathrm{ma}^{-1}$ over the upper $3500 \mathrm{~m}$. Basal velocities along an approximate flowline are reconstructed from the measured surface velocities using inverse methods. Control tests are used to validate the inversion scheme, and sensitivity tests are performed to evaluate the influence of the flow-law coefficient, shape factor and longitudinal averaging length. Inversion of the real data shows that basal motion accounts for $50-100 \%$ of the total surface motion along the flowline. Based on these results, and several other lines of evidence, we suggest this glacier may be undergoing a slow surge.
\end{abstract}

\section{INTRODUCTION}

The St Elias Mountains of Yukon and Alaska, North America, are rich in surge-type glaciers (Meier and Post, 1969). Some of these glaciers, including Variegated Glacier (e.g. Kamb and others, 1985) and Trapridge Glacier (e.g. Clarke and others, 1984; Frappé and Clarke, 2007), have been the subject of comprehensive study. Many surgetype glaciers in this region are thought to be of the 'Alaskan type' (Murray and others, 2003) with: (1) surges lasting 2-3 years; (2) characteristically rapid surge onset and termination; (3) surge velocities $\sim 10-100$ times faster than quiescent velocities; and (4) quiescent periods of 2040 years (Meier and Post, 1969). Frappé and Clarke (2007) recently reported on an unusual surge of Trapridge Glacier, which was characterized by an active phase of $\sim 20$ years and a surge velocity only four times that of the quiescent velocity. They suggested that the lack of vigour in the surge may be linked to low accumulation rates in recent years.

Here we examine the dynamics of a small surge-type glacier in the Donjek Range of the St Elias Mountains (Fig. 1), in order to distinguish between internal and external factors influencing the glacier flow regime. The work forms part of a broader study, one of whose aims is to evaluate the modulating role of glacier dynamics on the regional glacier response to climate. For this exercise to be carried out in the St Elias Mountains, glacier surges must be taken into account. We use inverse methods to examine the contribution of basal motion to overall ice-surface motion, as a means of characterizing the glacier dynamic regime. Geophysical inverse theory is widely used in seismology and mineral exploration, and has been gaining popularity among hydrologists and glaciologists. Inverse methods have recently been used by Waddington and others (2007) to infer accumulation rates from deep internal layers, by Eisen (2008) to determine the velocity field from isochrones in the firn and by Truffer (2004), whose inverse approach to estimate the basal speed of valley glaciers is the basis for the work described here.

\section{Study site}

The study glacier is $\sim 5 \mathrm{~km}$ long and $\sim 1 \mathrm{~km}$ wide, and occupies a tributary valley of Kaskawulsh Glacier, southwest Yukon, Canada. Kasper (1989), Johnson and Kasper (1992) and Johnson (1997) identified this glacier as surge-type, with a frontal margin chronology that differs from that of two adjacent glaciers feeding into a common valley that terminates in an ice-dammed lake. Johnson and Kasper (1992) identify deltas formed during surges of the study glacier and find evidence for disruption of drainage routes by these surges. Aerial photographs from 1951 and 1977 (Fig. 2) show the glacier during a surge and during quiescence, respectively. In the 1951 photograph, the glacier terminus was $>1 \mathrm{~km}$ further down-valley than at present. Another surge was photographed by P.G. Johnson in 1986/87. These photographs show a vertical ice cliff at the glacier terminus, extensive crevassing over the lower two-thirds of the glacier and at the glacier margin, water-filled crevasses and a surface that is clearly inflated relative to the present in the lower ablation area.

\section{DATA AND DERIVED MODEL INPUTS}

Data were collected on the study glacier during the 2006-08 summer field seasons from which several model inputs are derived. The primary data requirements of the model relate to glacier geometry and surface velocity. We obtained icesurface elevations over most of the main trunk of the glacier by real-time kinematic (RTK) global positioning system (GPS) surveying using Trimble R7 receivers with Zephyr geodetic antennas and a base station $\sim 200 \mathrm{~m}$ from the glacier margin. Dense spatial coverage of the glacier was achieved in all but a few inaccessible areas during surveys in 2006/07. Two steep tributaries of the trunk glacier, one of which is effectively disconnected, were not surveyed. De Paoli (2009) constructed a digital elevation model (DEM) of the glacier surface from the GPS data using kriging. From the DEM, an approximate flowline was determined and flowline profiles 

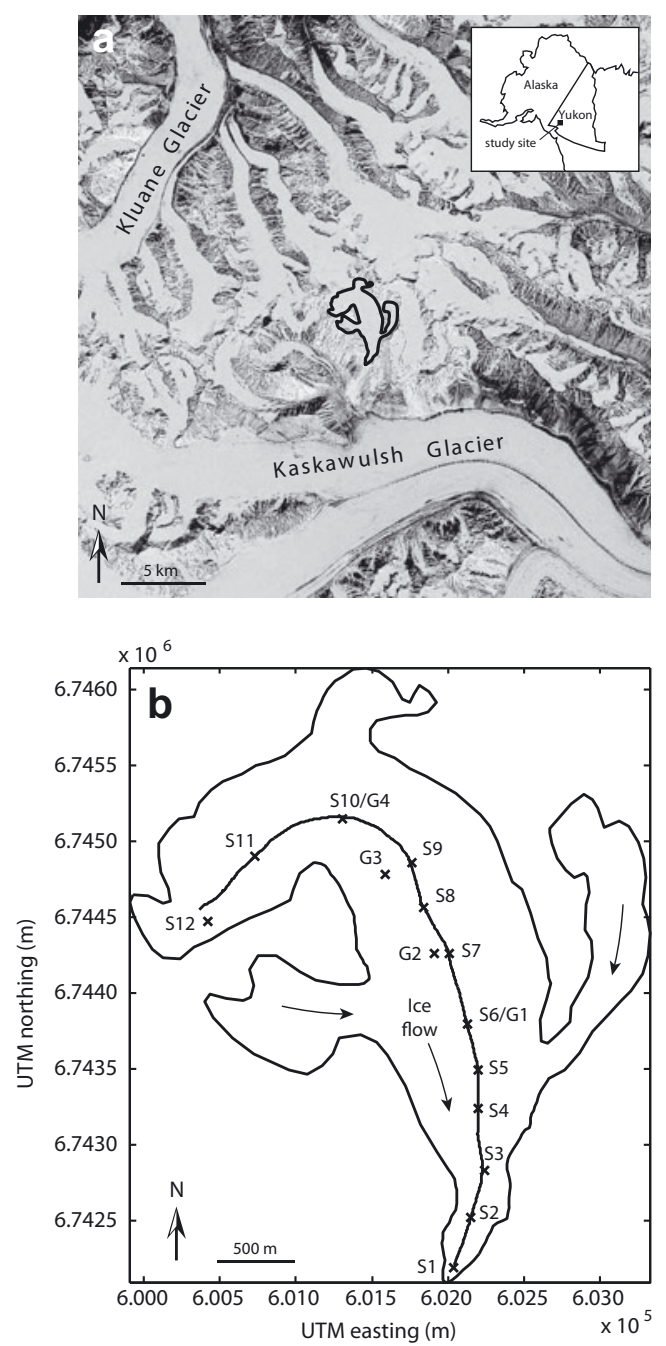

Fig. 1. Donjek Range study area (a) and study glacier outline with velocity stake locations labelled (b).

of local surface slope and shape factor were computed (Fig. 3).

We obtained ground-based ice-penetrating radar data in 2007/08 using a Narod and Clarke (1994) high-power impulse transmitter (pulse rate $512 \mathrm{~Hz}$ ), along with resistively loaded transmitting and receiving antennas, fabricated by Icefield Instruments Inc., to produce a centre frequency of $8 \mathrm{MHz}$. We used a National Instruments USB-5133 2CH $100 \mathrm{MS} \mathrm{s}^{-1}$ digitizer in place of an oscilloscope to capture the receiver signal, which was displayed on a miniature laptop computer. Data acquisition and analysis software were custom-designed by Blue System Integration Ltd, and include GPS capability (Rikaline SiRF III USB GPS receiver). We acquired data at $\sim 10 \mathrm{~s}$ intervals while travelling on skis. Each saved trace comprised a stack of 50-100 individual traces. Antennas were oriented parallel to the direction of motion for ease of travel. Transverse line spacing was $\sim 200 \mathrm{~m}$ over the lower two-thirds of the glacier, and we obtained clear bed reflections over much of this area. Adverse travelling conditions and frequent clutter in the radar returns resulted in patchy coverage over the upper third of the glacier. Several highly crevassed areas were avoided altogether. We assume a planar geometry and a velocity in ice of $1.68 \times 10^{8} \mathrm{~m} \mathrm{~s}^{-1}$ to compute ice thickness from the picked radar returns. We generate an ice-thickness map from
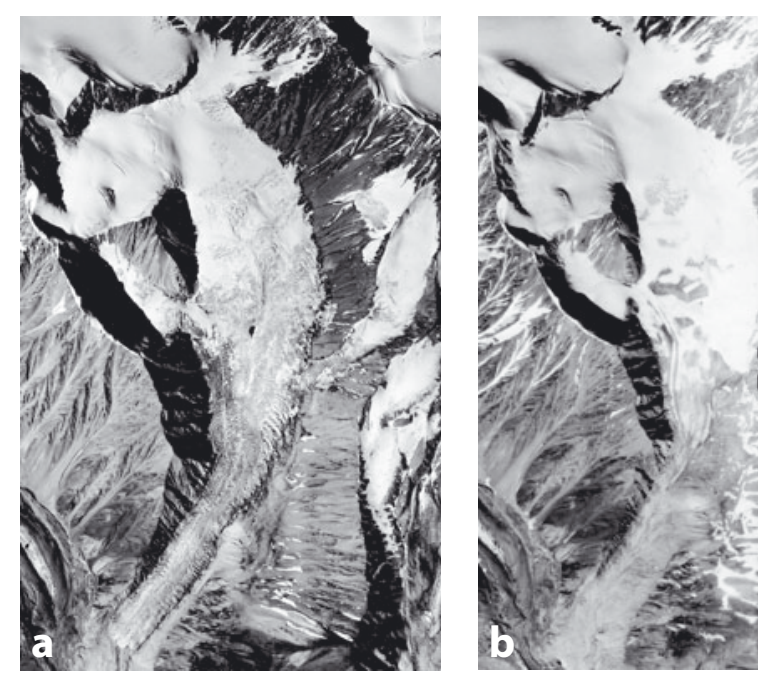

Fig. 2. Study glacier during a surge (1951 (a)) and during quiescence (1977 (b)). Note the difference in glacier front position between the two images, particularly compared to the front position of the adjacent glacier near the bottom left of the images. (Photographs: National Air Photo Library, Ottawa, Ontario: Department of Energy, Mines and Resources.)

these data by kriging (De Paoli, 2009), with data quality being taken into account following Flowers and Clarke (1999). A flowline profile of ice thickness is then extracted from this map.

Flowline profiles of glacier geometry, surface slope and shape factor (Fig. 3) are used as input to the inverse model. Glacier surface elevation ranges from 2000 to 2800 m a.s.l., with a mean surface slope of $10^{\circ}$. The lower $1500 \mathrm{~m}$ of the glacier is characterized by ice less than $\sim 60 \mathrm{~m}$ thick. The ice thickens up-glacier to $\sim 100 \mathrm{~m}$, on average, over the upper $2000 \mathrm{~m}$ of the flowline. This leads to creep velocities calculated according to Nye (1965) of $<10 \mathrm{~m} \mathrm{a}^{-1}$ over much of the flowline, with one prominent peak corresponding to a steep section located $\sim 3500 \mathrm{~m}$ from the terminus.

We established a network of velocity stakes $(10 \mathrm{ft}(\sim 3 \mathrm{~m})$ lengths of metal or PVC conduit) in 2006, including 12 stakes along the flowline (Fig. 1). These stakes, or a subset thereof, were surveyed on the dates listed in Table 1 using the GPS equipment described above. All 12 stakes were within a range of $\sim 400-3000 \mathrm{~m}$ from the base station. RTK GPS measurements were carried out by placing a roving antenna, mounted on a backpack or survey pole, adjacent to the stake on its upstream side. In this way we surveyed the position of the base of the stake rather than its top, in order

Table 1. Velocity stake measurement dates and resulting datasets. Most stakes were measured within 2 days for each survey period. Stakes G1 and G4 are used instead of S6 and S10 for summer 2006 and stakes G1, G2 and G3 are used instead of S6, S7 and S9 for summer 2007

\begin{tabular}{lcc}
\hline Start date & End date & Dataset name \\
\hline 11 Jul.-14 Jul. 2006 & 29-30 Jul. 2006 & Summer 2006 \\
27 Jul.-2 Aug. 2007 & 5-6 Aug. 2007 & Summer 2007 \\
11 Jul.-30 Jul. 2006 & 27-28 Jul. 2007 & Annual 2006/07 \\
27 Jul.-2 Aug. 2007 & 5-14 Jul. 2008 & Annual 2007/08
\end{tabular}



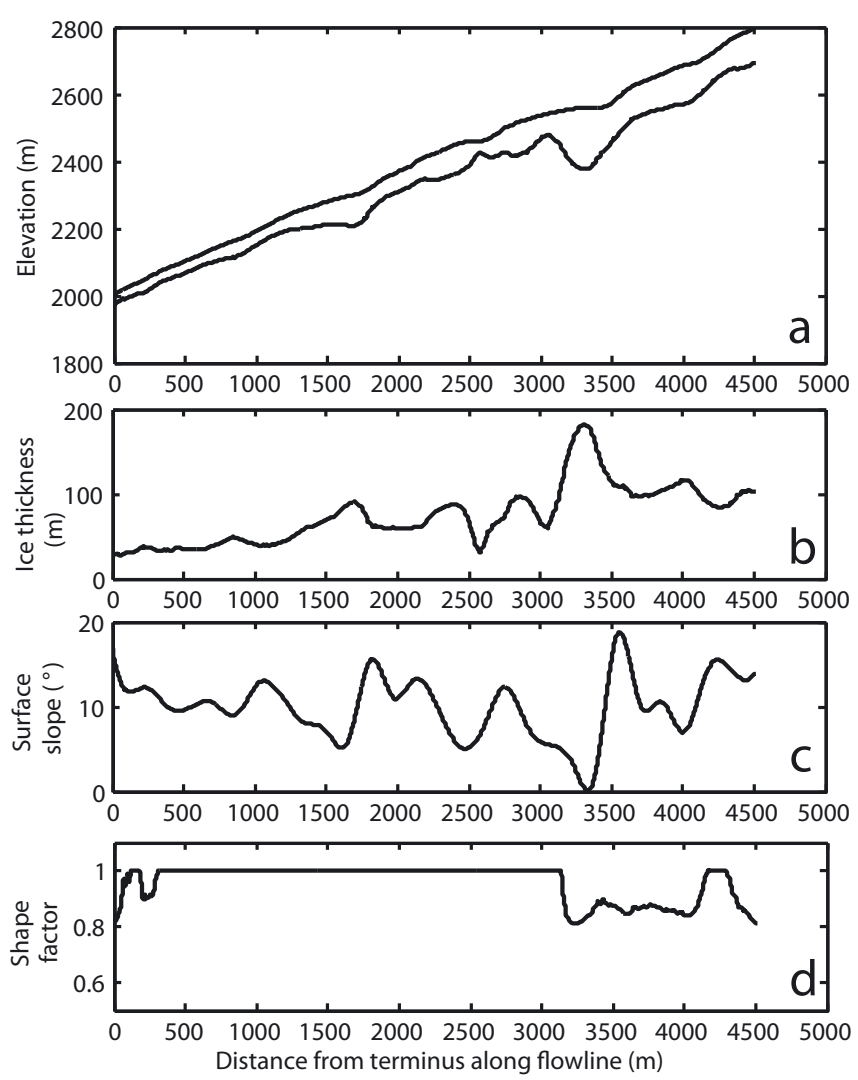

Fig. 3. Study glacier flowline profiles. (a) Surface and bed elevation, (b) ice thickness, (c) surface slope and (d) shape factor.

to avoid errors associated with stakes leaning as they melted out. Uncertainties in the horizontal-position measurements due to our methodology were estimated empirically to be $\pm 5 \mathrm{~cm}$, by having different team members measure the same stake in succession. Standard error propagation (e.g. Taylor, 1982) is used to assign errors to the velocities computed from measured stake positions. An additional set of four velocity stakes (G1-G4 in Fig. 1) was installed between 2006 and 2008. These stakes differ from those described above in that a GPS antenna was attached to the stake for the duration of the measurement period (up to $\sim 50$ days). The displacements of these stakes were determined using post-processing kinematic (PPK) GPS. In these cases, we only include an instrumental uncertainty of $\pm 1 \mathrm{~cm}$ on the measured positions. This gives rise to errors on the velocity calculations that are much lower than those for stakes S1-S12.

Velocities derived from stakes G1 and G4 were used to replace measurements missing from stakes S6 and S10, respectively, for the summer 2006 dataset, and velocities derived from stakes G1, G2 and G3 were used to replace measurements from stakes S6, S7 and S9, respectively, for the summer 2007 dataset. The measurement dates in Table 1 permit us to define four datasets; two of these we refer to as 'summer' datasets for convenience, though they cover only 1-2 weeks of the melt season. Although the 'summer' velocities we report are measured over short and slightly variable time periods, we have verified they are consistent with mean velocities measured over an extended time period (up to $\sim 50$ days) at stakes G1-G4.

Flowline velocities derived from each of the four datasets comprise the primary input to the inversion model. The

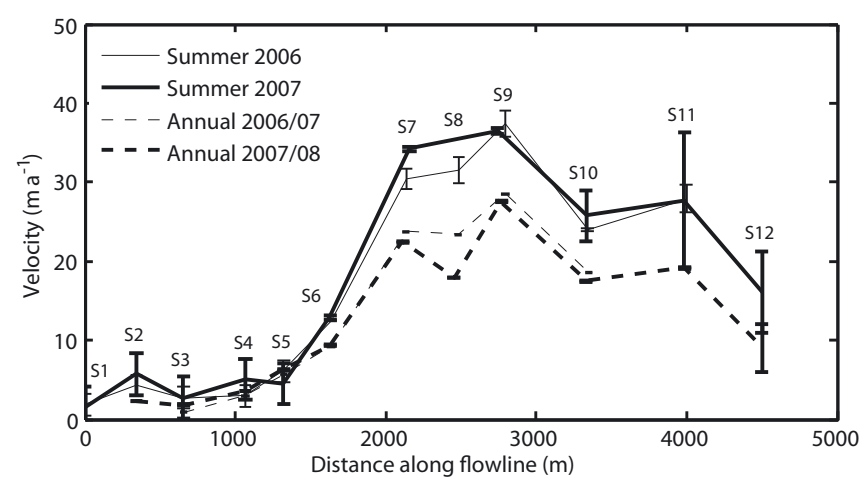

Fig. 4. Measured ice-surface velocities with associated uncertainties. Uncertainties on the annual data are very small, compared to those on the summer data, due to the longer period over which displacements were measured.

flowline velocity structure (Fig. 4) is similar for the four datasets, with velocities $<10 \mathrm{~m} \mathrm{a}^{-1}$ over the lowermost $1500 \mathrm{~m}$ of the flowline, and velocities $>10 \mathrm{ma}^{-1}$ above. Velocities are highest (up to $\sim 30 \mathrm{~m} \mathrm{a}^{-1}$ for the annual datasets and $>35 \mathrm{~m} \mathrm{a}^{-1}$ for the summer datasets) in a zone $\sim 1700-3300 \mathrm{~m}$ from the glacier terminus. Velocities above $3300 \mathrm{~m}$ are slightly lower than this peak. Figure 4 also reveals a distinct difference between the summer and annual velocities above $1500 \mathrm{~m}$ from the terminus, with an offset of $\sim 10 \mathrm{~m} \mathrm{a}^{-1}$ above $2000 \mathrm{~m}$ from the terminus. We might expect the true seasonality to be stronger than these data indicate, as our 'summer' measurements do not include the late spring and early summer.

\section{METHODS}

We use geophysical inverse methods to recover the basal velocity profiles from the measured surface velocities. The forward model used here is identical to that developed by Truffer (2004), which itself uses the model of Kamb and Echelmeyer (1986).

\section{Forward model}

The forward model requires an expression for the deformational or creep velocity of ice flowing down an inclined channel. Ice is treated as a non-linear viscous fluid whose rheology is described by Glen's flow law (Glen, 1955) with an exponent $n=3$. We consider an idealized slab glacier of uniform thickness, $h$, and uniform bed inclination, $\alpha$. Using this glacier geometry and the assumption of laminar flow, Paterson (1994, p. 251) showed that the deformational velocity at the surface of the glacier can be expressed analytically as

$$
u_{\mathrm{c}}=\frac{2 A}{n+1}(\rho \mathrm{g} f \sin \alpha)^{n} h^{n+1},
$$

where $A$ is the flow-law coefficient, $\rho$ is ice density, $g$ is gravitational acceleration and $f$ is the shape factor. The shape factor accounts for the reduction in ice-flow speed along the glacier centre line due to drag exerted by the valley walls (Nye, 1965). The values of $f, \alpha$ and $h$ are determined from the data described above. Examination of the bed DEM leads to the choice of shape factors appropriate to a semi-elliptical idealized bed shape. The value of $A$ is estimated as described in the Appendix. 
A model is needed to link the glacier surface velocity to the contributions from creep and basal flow (sliding and substrate deformation). Longitudinal variations in slope and thickness cause longitudinal compression or extension that varies over the length of the glacier (Nye, 1952), giving rise to non-zero longitudinal stress gradients. The coupling introduced by the longitudinal stress gradients can considerably modify the velocity from that calculated using local slope and thickness (Equation (1)). Kamb and Echelmeyer (1986) parameterize the longitudinal stressgradient coupling in terms of longitudinal averages of local slope and thickness. They write the creep velocity, $u$, at any position, $x$, along the length of the glacier as

$$
u(x)=u_{\text {obs }}\left(x_{0}\right) \mathrm{e}^{T(x)-T\left(x_{0}\right)},
$$

where $u_{\mathrm{obs}}\left(x_{0}\right)$ is the velocity at a point of observation along the flowline and $T$ is defined as

$$
T(x)=\int_{x-2 l}^{x+2 l}[n \ln \alpha f+(n+1) \ln h] W_{l}\left(x^{\prime}-x\right) \mathrm{dx} x^{\prime}
$$

The relative coordinate, $x^{\prime}-x$, is the distance between a point $x$ on the flowline and a point $x^{\prime}$ of measurement. $W_{l}$ is a weighting function, and $l$, the longitudinal coupling length, depends on rheological parameters and is generally about one to three times the ice thickness (Kamb and Echelmeyer, 1986). Equations (2) and (3) correspond to Kamb and Echelmeyer's equations (35a and 35b).

Truffer (2004) combined and adapted these equations into the following form:

$$
\ln u_{\mathrm{s}}(x)=\int_{0}^{L} g\left(x^{\prime}-x\right) \ln \left(u_{\mathrm{c}}\left(x^{\prime}\right)+u_{\mathrm{b}}\left(x^{\prime}\right)\right) \mathrm{d} x^{\prime},
$$

where $u_{\mathrm{s}}$ is the observed surface velocity, $u_{\mathrm{b}}$ is the basal velocity along the centre line of the glacier, $L$ is the total length of the glacier and $x$ is the longitudinal flowline coordinate. The weighting function, $g$, corresponds to the function $W_{l}$ of Kamb and Echelmeyer (1986) and is defined as

$$
g\left(x^{\prime}-x\right)=C \mathrm{e}^{-\frac{\left|x^{\prime}-x\right|}{I}} .
$$

A value of three times the local ice thickness is used for I (the longitudinal coupling length) in the following. The length $4 I$ is called the 'averaging length' and provides a measure of the distance over which the effects of varying slope and thickness are averaged. $C$ is a normalizing factor whose purpose is to ensure that

$$
\int_{0}^{L} g\left(x^{\prime}-x\right) d x^{\prime}=1
$$

Equation (4) constitutes the foundation of the forward model and can be used to estimate glacier surface velocities, given an appropriate boundary condition at the glacier bed.

\section{Linear inverse problem}

The forward model can be written mathematically as an inner product:

$$
d_{j}=\left(g_{j}, m\right), \quad j=1, \ldots, N,
$$

where $d_{j}$ are the data, $m$ is the model and $g_{j}$ are continuous kernel functions calculated using the weighting function, $g$.
Using this notation, the forward model can be formulated as

$$
\ln u_{\mathrm{s}}=\left[g, \ln \left(u_{\mathrm{c}}+u_{\mathrm{b}}\right)\right]
$$

(Truffer, 2004). In Equation (8), the data $d_{j}=\ln u_{\mathrm{s}}$ are $N$ discrete real numbers, while the model $m=\ln \left(u_{\mathrm{c}}+u_{\mathrm{b}}\right)$ is a function of a Hilbert space, $H$. Following the approach of Truffer (2004), we rewrite Equation (8) as

$$
\ln u_{\mathrm{s}}-\left[g, \ln u_{\mathrm{c}}\right]=\left[g, \ln \left(1+\frac{u_{\mathrm{b}}}{u_{\mathrm{c}}}\right)\right] .
$$

With this notation, the data become $d_{j}=\ln u_{\mathrm{s}}-\left[g\right.$, $\left.\ln u_{\mathrm{c}}\right]$ and the model $m=\ln \left(1+u_{\mathrm{b}} / u_{\mathrm{c}}\right)$. Using the surface velocity measurements, as well as measurements of local slope and ice thickness, the data, $d_{j}$, can be evaluated at each of the $N$ longitudinal coordinate positions, $x_{j}$, for which measurements of surface velocity exist.

Numerical treatment of the inverse problem requires that the model be evaluated at a finite number of locations. Both the model and kernel function are discretized into $M$ components, with $M>N$, so the inverse problem is underdetermined. The kernel functions depend on the relative coordinate, $x^{\prime}-x$, such that there is one kernel function, $g_{j}$, associated with each of the $N$ data. Computation of the $N$ kernel functions at each of the $M$ discrete spatial locations results in the $N \times M$ Gram matrix, usually denoted $G$ (Parker, 1994, p. 36). The Gram matrix relates the data to the model such that Equation (9) becomes

$$
\ln u_{\mathrm{s}}-\left[g, \ln u_{\mathrm{c}}\right]=G \ln \left(1+\frac{u_{\mathrm{b}}}{u_{\mathrm{c}}}\right) .
$$

Finding an accurate model $m$ involves inverting $G$. In most underdetermined problems, $G$ is singular and a special technique is needed to perform the inversion.

\section{Model norm and misfit function}

The inverse problem is underdetermined, so the solution is non-unique and an infinite number of models satisfy the data. The process of selecting the best model is called 'optimization' and is usually carried out by minimizing a model norm (Parker, 1994, p. 34). Following the method of Occam's inversion (Constable and others, 1987), we choose a norm that favours the smoothest model by minimizing the second derivative. The model norm is expressed in terms of a weighting matrix, $W_{\mathrm{m}}$, containing coefficients of a secondorder finite-difference stencil:

$$
W_{\mathrm{m}}=\frac{1}{(\Delta x)^{2}}\left[\begin{array}{cccccccc}
1 & -2 & 0 & & & & \\
1 & -2 & 1 & & & & 0 & \\
& 1 & -2 & 1 & & & & \\
& & & \ldots \ldots & & & \\
& & & & 1 & -2 & 1 & \\
& 0 & & & & 1 & -2 & 1 \\
& & & & & 0 & -2 & 1
\end{array}\right]
$$

where $\Delta x$ is the grid spacing of the model. The first and last rows of the matrix contain coefficients reflecting boundary conditions adapted to the problem to ensure that $W_{\mathrm{m}}$ is invertible. The weighting matrix, $W_{\mathrm{m}}$, is applied to the model, $m$, to form a quantity known as the model objective function, $\phi_{\mathrm{m}}$, which can be expressed as a norm or in matrix form as

$$
\phi_{\mathrm{m}}=\left\|W_{\mathrm{m}} m\right\|^{2}=m W_{\mathrm{m}}^{\top} W_{\mathrm{m}} m
$$


where $W_{\mathrm{m}}^{\top}$ is the transpose of the weighting matrix. The optimization process finds smooth models that fit the data by minimizing the model objective function, $\phi_{\mathrm{m}}$, subject to the condition $d=G m$.

Because the data contain errors, we construct a misfit function that is used to control how precisely the data are predicted. Like the model objective function, the misfit function is expressed as a norm and is parameterized using a weighting matrix:

$$
W_{\mathrm{d}}=\left[\begin{array}{ccccc}
\frac{1}{\sigma_{1}} & & & 0 & \\
& \frac{1}{\sigma_{2}} & & & \\
& & \ldots & \frac{1}{\sigma_{N-1}} & \\
& 0 & & & \frac{1}{\sigma_{N}}
\end{array}\right],
$$

where $\sigma_{j}$ are the standard deviations of the errors. The standard rules of error propagation are used to assign errors to the data, based on errors in the measured surface velocities. The misfit function, $\phi_{d}$, can then be written

$$
\phi_{\mathrm{d}}=\left\|W_{\mathrm{d}}(d-G m)\right\|^{2},
$$

where the product $G m$ is the predicted data, that is to say, the data that are obtained when the model resulting from the inversion is used as input to the forward model. It has been shown that, in most cases, the criterion $\phi_{\mathrm{d}}=N$ yields models that fit the data within the error (Parker, 1994, p. 192). As a final step, we introduce a reference model equal to the local difference between the measured surface velocity and the calculated velocity due to deformation. We find that using a reference model results in better recovery of basal velocity profiles in control tests (De Paoli, 2009), but has little impact on computational performance. The inverse problem now becomes:

$$
\begin{array}{ll}
\operatorname{minimize} \quad \phi_{\mathrm{m}} & =\left\|W_{\mathrm{m}}\left(m-m_{\mathrm{ref}}\right)\right\|^{2} \\
& =\left(m-m_{\mathrm{ref}}\right) W_{\mathrm{m}}^{\top} W_{\mathrm{m}}\left(m-m_{\text {ref }}\right) \\
\text { subject to } \quad \phi_{\mathrm{d}} & =\left\|W_{\mathrm{d}}(d-G m)\right\|^{2} \leq N .
\end{array}
$$

\section{Singular-value decomposition}

We solve the inverse problem using two methods: a straight minimization with a Lagrange multiplier, and a singularvalue decomposition (SVD). De Paoli (2009) investigated both methods, and found SVD simpler to implement in this case, as direct minimization occasionally led to poorly conditioned problems that would require special treatment. This study therefore employs SVD. The misfit and model norm are transformed by first defining $x$ such that

$$
x=W_{\mathrm{m}}\left(m-m_{\text {ref }}\right) .
$$

The misfit criterion can then be written

$$
\phi_{\mathrm{d}}=\|A x-b\|^{2},
$$

where $A$ is an $N \times M$ matrix such that $A=W_{\mathrm{d}} G W_{\mathrm{m}}^{-1}$, and $b$ is an $N \times 1$ vector such that $b=W_{\mathrm{d}} d_{\mathrm{obs}}-W_{\mathrm{d}} G m_{\text {ref. }}$. The inverse problem then becomes:

$$
\begin{array}{ll}
\operatorname{minimize} & \phi_{\mathrm{m}}=\|x\|^{2} \\
\text { subject to } & \phi_{\mathrm{d}}=\|A x-b\|^{2} \leq N .
\end{array}
$$

The matrix $A$ is rectangular and can be written in the form of a spectral factorization (Parker, 1994, p. 145), also called singular-value decomposition:

$$
A=U \Lambda V^{\top}
$$

where $U$ and $V$ are matrices containing the eigenvectors of $A A^{\top}$ and $\Lambda$ is the matrix containing the eigenvalues of $A A^{\top}$ (eigenvalues of $A A^{\top}$ are singular values of $A$ ). The matrices $U$ and $V$ are square and have $N$ and $M$ components, respectively, but the eigenvalue matrix $\Lambda$ is not square $(N \times M)$ and is therefore singular. Because the purpose of the inversion process is to recover the model $m$ from Equation (17), $x$ must be computed. $\Lambda$ must therefore be rendered square. This is done by recognizing that many of the eigenvalues are zero, and by truncating $\Lambda$ to keep only the first $p$ non-zero eigenvalues (Parker, 1994, p. 148). Eigenvectors are truncated accordingly. Expressed as a singular-value decomposition (Equation (21)), matrix $A$ is now invertible. The variable $x$ becomes

$$
x=V F \Lambda^{-1} U^{\top} b,
$$

with $F$ the identity matrix, which will become important during the regularization process. The model $m$ can then be recovered from $x$ using Equation (17). The model norm, $\phi_{\mathrm{m}}$, and misfit, $\phi_{\mathrm{d}}$, are computed as

$$
\begin{gathered}
\phi_{\mathrm{m}}=\left(U^{\top} b\right)^{\top}\left(L^{-1} T\right)^{2}\left(U^{\top} b\right) \\
\phi_{\mathrm{d}}=\left\|\left(F-I_{p}\right) U^{\top} b\right\|^{2}+\left\|\left(I_{N}-U U^{\top}\right) b\right\|^{2},
\end{gathered}
$$

where $I_{p}$ and $I_{N}$ are $p \times p$ and $N \times N$ identity matrices, respectively.

The inversion is carried out by minimizing a model norm, subject to a misfit criterion. To optimize the result, a balance is sought between the two in the form of regularization. This is done by truncating the SVD a second time. The appropriate number of eigenvalues, J, that should be retained is determined by identifying the point at which the misfit attains the value of $N$. Smaller eigenvalues are then ignored. While $F=I$ when computing the full SVD, $F$ is now altered so that its first $J$ values are ones and the rest of its values are zeros. This sets all eigenvalues $\lambda_{i>1}$ to zero when computing $x$ (Equation (22)). The regularized model, $m$, is then computed using Equations (17) and (22), and the basal velocity profile, $u_{\mathrm{b}}$, is recovered from the model $m$ using Equation (9).

\section{RESULTS}

Control tests of the algorithm were performed to test the validity of the inversion scheme described above. We then invert the measured surface velocities and examine the sensitivity of inversion results to three key parameters.

\section{Control tests}

In a successful control test, a synthetic basal velocity profile is accurately recovered by the inversion algorithm. The control tests proceed as follows:

1. a synthetic basal velocity profile (or synthetic model) is chosen; 

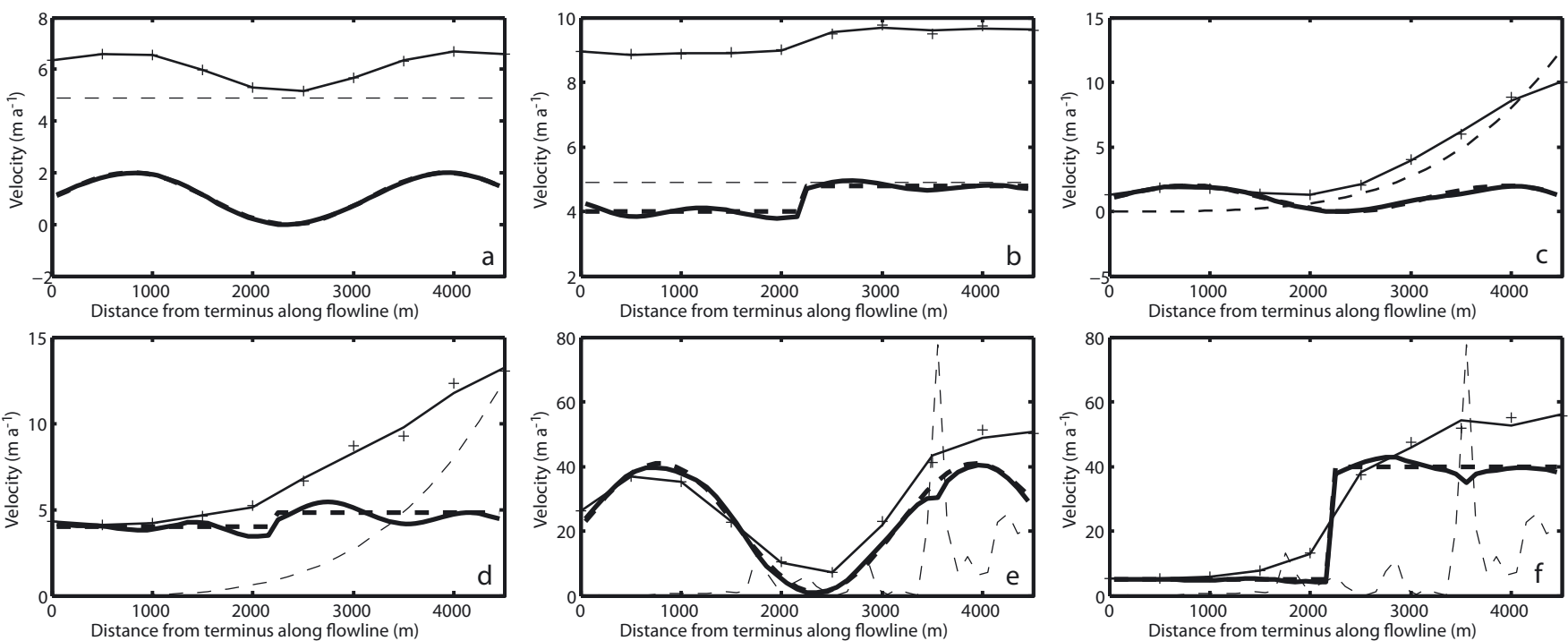

Fig. 5. Control test results shown as flowline profiles of synthetic and recovered basal velocity (bold dashed and solid curves, respectively), synthetic surface velocity with noise added (crosses), predicted surface velocity (fine solid curve) and deformational velocity (fine dashed curve). (a) Test 1: slab geometry/sinusoidal basal velocity. (b) Test 2: slab geometry/step basal velocity. (c) Test 3: wedge geometry/sinusoidal basal velocity. (d) Test 4: wedge geometry/step basal velocity. (e) Test 5: real geometry/sinusoidal basal velocity. (f) Test 6: real geometry/step basal velocity.

2. the synthetic basal velocity profile is used as input to the forward model to generate a synthetic surface velocity profile;

3. the synthetic surface velocities are perturbed by adding a small random component of noise $(1 \%$ of the mean surface velocity);

4. the perturbed synthetic data are computed from the perturbed synthetic surface velocities using Equation (10);

5. the perturbed dataset is run through the inversion algorithm to recover a basal velocity profile;

6. this basal velocity profile is input to the forward model to generate a set of predicted surface velocities.

Comparing the synthetic and recovered models, as well as the synthetic and predicted data, allows us to assess the performance of the algorithm and the inversion method. In the six control tests presented here, we use sinusoidal and step-like synthetic basal velocity profiles, and slab-like, wedge-shaped and real glacier geometries (Table 2). Other control tests were performed without a reference model and with alternative solution methods (De Paoli, 2009) but are not presented here.

In all six tests, the synthetic data are predicted closely and the synthetic model is recovered fairly well (Fig. 5). The rectangular basal velocity profile (tests $2,4,6$ ) is less well reproduced than the sinusoidal basal velocity profile (tests $1,3,5)$, as expected for a method constructed to select the smoothest model. The quality of the results also depends on glacier geometry, with the recovered model deteriorating from the simple slab glacier (tests 1 and 2), to the more complex wedge-shaped glacier (tests 3 and 4), to the glacier with real geometry (tests 5 and 6). This effect is also linked to an increase in the amplitude of the synthetic basal velocity profile, as the synthetic surface velocity depends on both the synthetic basal velocity profile and the glacier geometry. Large amplitudes of the synthetic basal velocity model were chosen for the control tests on real geometry to make the contributions from deformation and basal motion of similar magnitude.

Table 2. Glacier geometry and prescribed model parameters for the inversion control tests. Values in parentheses are averages. The thickness and slope profiles used for the real glacier geometry are presented in Figure 3. All shape factors are calculated for semi-elliptical beds

\begin{tabular}{|c|c|c|c|c|c|c|}
\hline Parameter & Test 1 & Test 2 & Test 3 & Test 4 & Test 5 & Test 6 \\
\hline Glacier geometry & Slab & Slab & Wedge & Wedge & Real & Real \\
\hline Ice thickness type & Constant & Constant & Variable & Variable & Variable & Variable \\
\hline Ice thickness (m) & 100 & 100 & $10-200$ & $10-200$ & 25-182 (78) & $25-182(78)$ \\
\hline Slope type & Constant & Constant & Constant & Constant & Variable & Variable \\
\hline Slope $\left(^{\circ}\right)$ & 5 & 5 & 2.54 & 2.54 & $0-19(10.1)$ & $0-19(10.1)$ \\
\hline Shape factor & 1 & 1 & 1 & 1 & $0.8-1.0(0.96)$ & $0.8-1.0(0.96)$ \\
\hline Synthetic basal velocity model & Sinusoidal & Rectangular & Sinusoidal & Step & Sinusoidal & Step \\
\hline Minimum basal velocity $\left(\mathrm{ma}^{-1}\right)$ & 0 & 4.0 & 0 & 4.0 & 0 & 4.0 \\
\hline Maximum basal velocity $\left(\mathrm{ma}^{-1}\right)$ & 2.0 & 4.8 & 2.0 & 4.8 & 2.0 & 4.8 \\
\hline Wavelength of basal velocity (m) & 3000 & - & 3000 & - & 3000 & - \\
\hline Step location along flowline (m) & - & 2250 & - & 2250 & - & 2250 \\
\hline
\end{tabular}



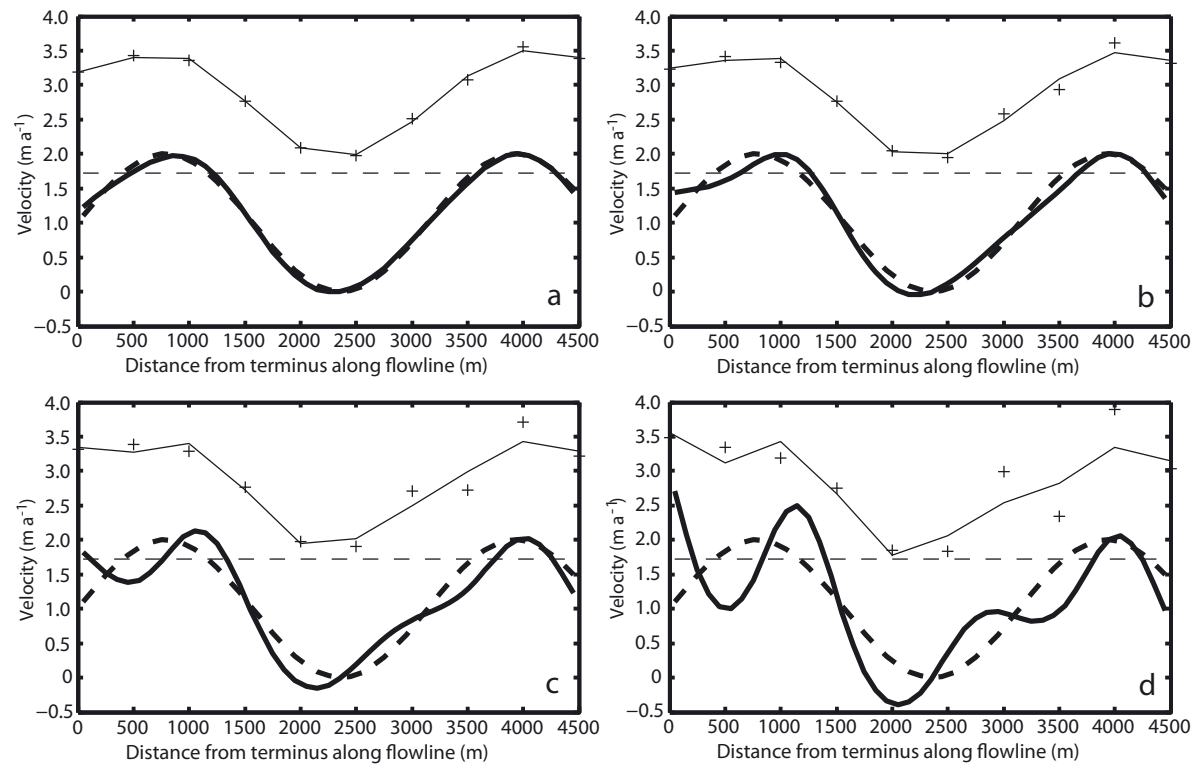

Fig. 6. Control test results with variable amounts of noise for a slab-like glacier with a sinusoidal basal velocity profile (test 1). Noise amounts: (a) $2 \%$, (b) $5 \%$, (c) $10 \%$ and (d) $20 \%$ of the mean synthetic surface velocity. Profiles shown are: synthetic and recovered basal velocity (bold dashed and solid curves, respectively), synthetic surface velocity with noise added (crosses), predicted surface velocity (fine solid curve) and deformational velocity (fine dashed curve).

An additional test is performed to examine the influence of variable amounts of noise on the data. This test is conducted with a slab-like glacier geometry and a sinusoidal basal velocity profile (test 1 ). Synthetic surface velocity data generated from this model are first perturbed with noise amounts of $2 \%, 5 \%, 10 \%$ and $20 \%$ of the mean synthetic surface velocity and then inverted. Figure 6 shows the reduction in accuracy of the recovered model with increasing noise, and can be compared to Figure 5 where noise is $1 \%$. The uncertainty in the measured annual surface velocity is $<1 \%$ over the upper $3500 \mathrm{~m}$ of the glacier and $<5 \%$ over the lower $1500 \mathrm{~m}$ for both the 2006/07 and 2007/08 annual datasets. For the summer 2006 and 2007 datasets, the error amounts to $<5 \%$ over the upper $3500 \mathrm{~m}$ but far exceeds $20 \%$ over the lower $1500 \mathrm{~m}$. These high relative errors are a product of low measured velocities $\left(<10 \mathrm{~m} \mathrm{a}^{-1}\right)$.

\section{Inversion of real data}

We invert each of the four datasets presented in Table 1. The resulting basal velocity and predicted surface velocity profiles are shown in Figure 7 . It is important to note that calculated errors have been multiplied by a factor of 17 , as explained below, to obtain the results shown in Figure $7 \mathrm{a}$ and $\mathrm{b}$ for the annual datasets. Inversion of the annual datasets using the original calculated errors produces basal velocity profiles that exhibit unrealistic oscillations between 2000 and $3000 \mathrm{~m}$ along the flowline (Fig. 8). Similar oscillations have been reported by Truffer (2004) for inversions that do not take uncertainties into account. The errors associated with the annual data are, indeed, so small that the inversion effectively attempts to fit the data exactly. This interpretation of the cause of the oscillations is substantiated by tests performed using a range of data errors (not shown). A factor of 17 was experimentally found to suppress oscillations in the basal velocity model for the annual datasets. The increased errors used to generate the annual basal velocity profiles are of the same order of magnitude as the uncertainty in the summer datasets.
Increasing the magnitude of the errors can be justified by the fact that the original calculated errors do not account for uncertainties in the position of the flowline itself, nor the fact that some poles are slightly off the flowline and may have velocities that are not tangential to it. More importantly, the forward model itself is only an approximation of reality and therefore introduces an additional source of unquantified error.

The percentage contribution of basal motion, defined as

$$
P=100 \% \frac{u_{\mathrm{b}}}{u_{\mathrm{b}}+u_{\mathrm{c}}}
$$

is similar for all four datasets (Fig. 9). Basal motion accounts for $\sim 60-100 \%$ of the total surface motion over the lower $\sim 3400 \mathrm{~m}$ of the glacier and ranges between 0 and $80 \%$ above. The only substantial difference between summer and annual datasets occurs over the lowermost $1500 \mathrm{~m}$ of the glacier, where basal motion accounts for a higher fraction of summer velocities.

\section{Sensitivity tests}

Several parameters used in the inversion are subject to uncertainty that cannot be eliminated with the available field measurements. In these cases, we adopt values that are qualitatively consistent with the study glacier environment or values prescribed in the literature. This is the case for the shape factor, used to parameterize the effect of drag from the valley walls, and for the longitudinal coupling length, taken as three times the local ice thickness. Kamb and Echelmeyer (1986) suggest that the coupling length is itself a function of basal motion. This parameter could thus be better constrained using an iterative approach. Englacial temperature was modelled (see Appendix) in order to select an appropriate flow-law coefficient. We conduct three tests to outline the impact of the shape factor, $f$, longitudinal coupling length, $I$, and flow-law coefficient, $A$, on modelled basal motion. We present results only for the annual 2007/08 

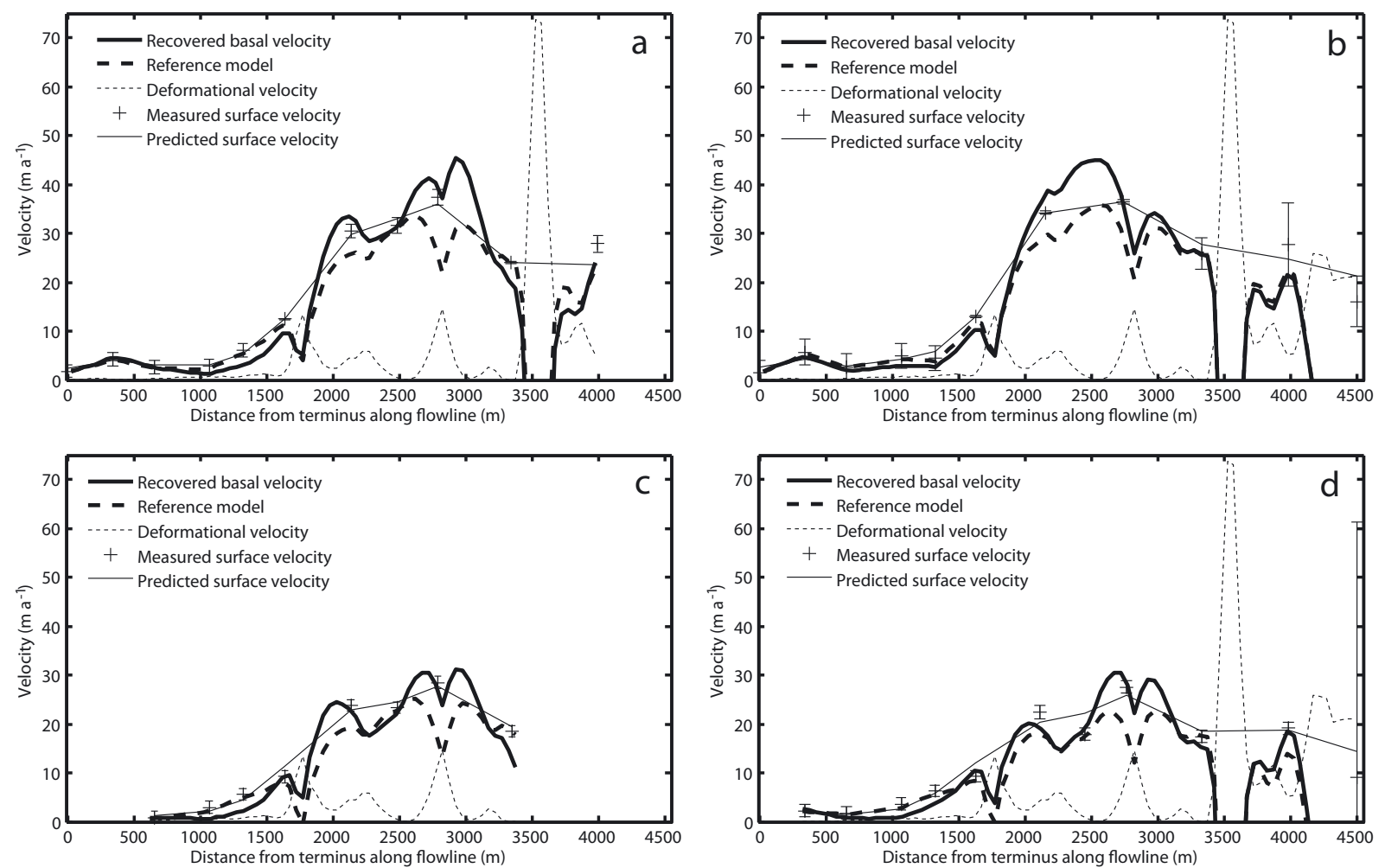

Fig. 7. Inversion of real data: (a) summer 2006; (b) summer 2007; (c) annual 2006/07; (d) annual 2007/08. The predicted surface velocity is plotted as a continuous curve to avoid confusion with the measured surface velocity but should not be interpreted as a continuous profile. The errors associated with the annual datasets $(c, d)$ have been increased from their original estimates.

dataset, as they are broadly representative of results from all the datasets.

In the control tests and the inversion of real data, the bed was assumed to have a semi-elliptical shape. This choice was motivated by the geometry of the valley and the bed DEM. Here we experiment with rectangular and parabolic beds with shape factors given by Paterson (1994, p. 269). Figure 10 presents the shape-factor profiles, along with the contribution of basal motion computed from the inversion of the data generated using these shape factors. Profiles of the contribution of basal motion computed with the three bed shapes are identical over most of the length of the glacier and differ only slightly between 3000 and $4500 \mathrm{~m}$.

Figure 11 shows the result of varying the longitudinal coupling length from the default value of three ice

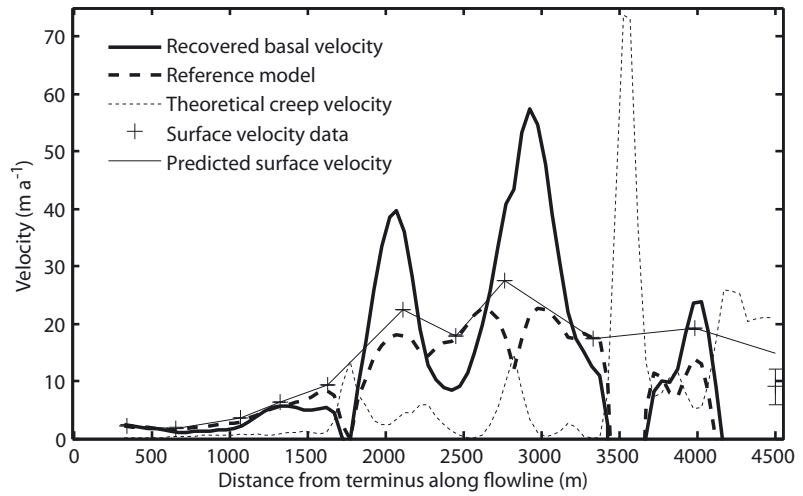

Fig. 8. Inversion of the $2007 / 08$ annual velocity data with original errors. thicknesses $(I=3 h)$ to one, two, four and five ice thicknesses. The effect of the value of $I$ on the contribution of basal motion is only significant when $/$ is increased to four or five ice thicknesses. Significant deviations are restricted to short sections of the flowline in each case.

The procedure we used to select an appropriate value of the flow-law coefficient is described in the Appendix. The default value corresponds to an effective ice temperature of $-2{ }^{\circ} \mathrm{C}$. The contribution of basal motion is recomputed for flow-law coefficients corresponding to effective ice temperatures of $0,-1$ and $-3^{\circ} \mathrm{C}$ (see Table 3). Figure 12 shows that there is little change in the contribution of basal motion for an effective temperature of $-3^{\circ} \mathrm{C}$, but that the contribution of basal motion decreases significantly for effective temperatures of $-1^{\circ} \mathrm{C}$ and $0^{\circ} \mathrm{C}$. The temperature

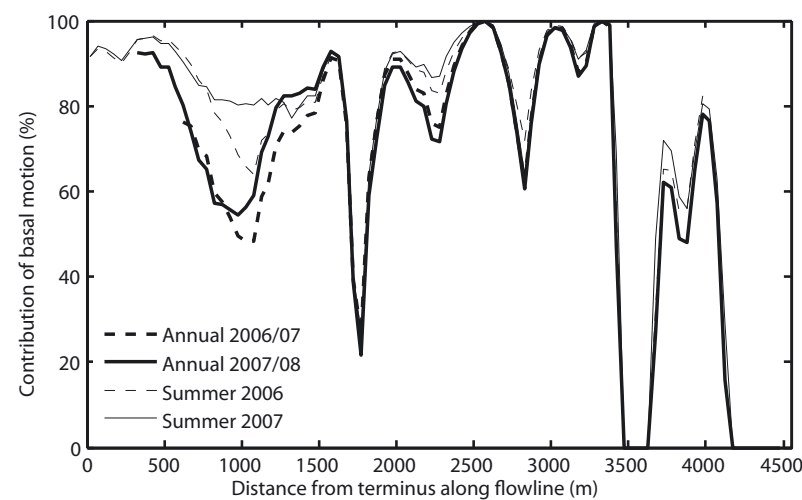

Fig. 9. Contribution of basal motion along the flowline for inversion results shown in Figure 7. 

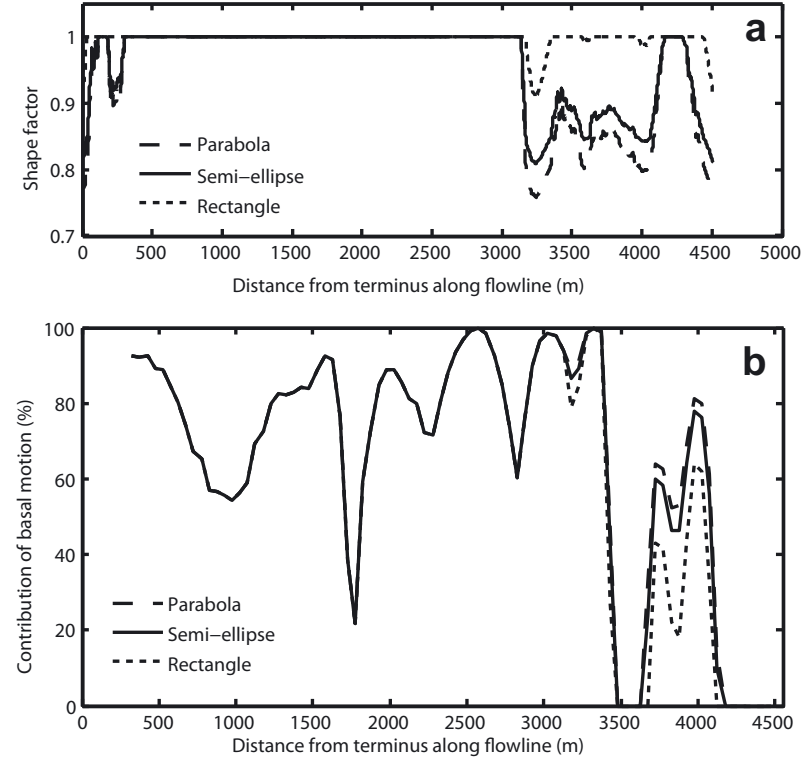

Fig. 10. Sensitivity test with a variable shape factor for the 2007/08 annual dataset. (a) Shape-factor profiles. (b) Contribution of basal motion for each shape factor. In both (a) and (b) the thick solid curve represents the shape factor used in the control tests and inversion of real data.

modelling detailed by De Paoli (2009), summarized in the Appendix, suggests that effective temperatures less than $-3^{\circ} \mathrm{C}$ are not realistic for the study glacier. An effective temperature between 0 and $-2{ }^{\circ} \mathrm{C}$ is more plausible; thus the contribution of basal motion may be lower than shown in Figure 9, but still accounts for $>50 \%$ of the total glacier motion over most of the length of the flowline. Note that the actual glacier flow velocities are very low over the lower $1500 \mathrm{~m}$ of the glacier where the largest percentage variations in basal motion occur (Fig. 12).

\section{INTERPRETATION AND DISCUSSION}

The study glacier exhibits three distinct zones, both dynamically and morphologically, based on observations made in 2006-08. The lower $\sim 1700 \mathrm{~m}$ of the glacier length is free of crevasses and presents a less variable surface slope than the rest of the glacier. The zone between $\sim 1700$ and $3300 \mathrm{~m}$ along the flowline exhibits surface undulations and extensive crevassing in many areas. The zone above $3300 \mathrm{~m}$ is also crevassed, with surface slopes that vary in association with two prominent icefalls. This pattern is reflected in the surface velocity measurements, with the lowest velocities over the lowermost $\sim 1700 \mathrm{~m}$ of the flowline, velocities from $\sim 20$ to $35 \mathrm{~m} \mathrm{a}^{-1}$ in the central region $(1700-3300 \mathrm{~m})$, and from $\sim 10$ to $30 \mathrm{~m} \mathrm{a}^{-1}$ above this. We interpret the nearly stagnant ice over the lower glacier to be a remnant of the 1986/87 surge based on: (1) photographic evidence of the ice in this area during the surge being much thicker and clearly involved in the surge itself; (2) the glacier terminus currently being $\sim 1 \mathrm{~km}$ further down-valley than it was in 1977 (prior to the last surge); and (3) the marked denudation (erosional stripping) of the valley walls adjacent to and downstream of the lower reaches of the glacier. The relatively high flow velocities above $\sim 1700 \mathrm{~m}$ are consistent with the observation of ongoing crevasse formation in this area. In the accumulation area, fresh crevasses are recognized as narrow

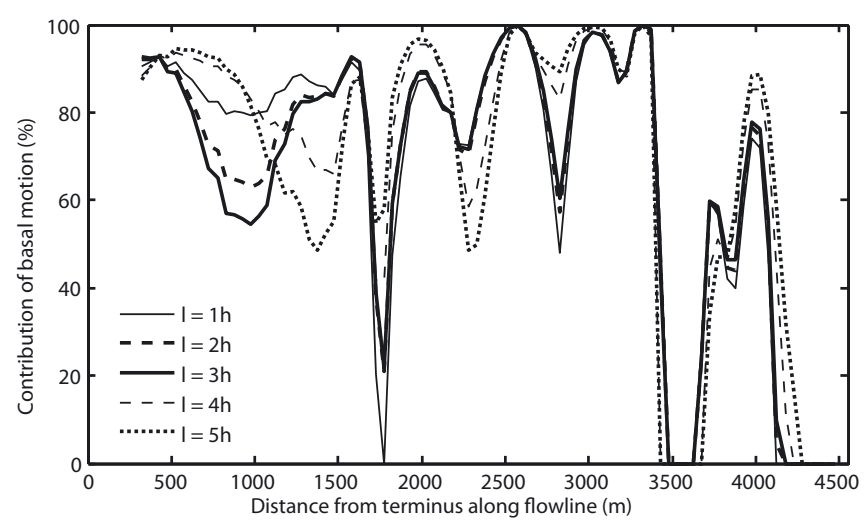

Fig. 11. Sensitivity test for variable longitudinal coupling lengths, $I$, for the $2007 / 08$ annual dataset. A value of $I=3 h$ was used in the control tests and inversion of real data.

fractures at the surface where the small-scale geometry is mirrored in detail on both sides of the fracture. In the ablation area, fresh crevasses have been encountered near stakes where the local crevasse geometry is well known from repeat visits to the sites.

Our inverse modelling reveals that basal motion is responsible for $50-100 \%$ of the total glacier motion for both summer and annual velocity datasets. The contribution of basal motion is highest in the central region of the glacier ( $1700-3300 \mathrm{~m})$, over $80 \%$ across a significant fraction of this zone for most model parameters. The surface undulations observed between $\sim 1700$ and $3300 \mathrm{~m}$ from the terminus (Fig. 13) are consistent with the high contribution of basal motion modelled over this area for all datasets. Such a flow regime is expected to enhance the transmission of basal topography to the glacier surface, as demonstrated by Gudmundsson and others (2003). The contribution of basal motion is lowest in the upper region (above $3300 \mathrm{~m}$ ), though it still reaches a maximum of $\sim 80 \%$. The dynamics of the lower glacier (below $\sim 1700 \mathrm{~m}$ ) are the most difficult to interpret, because of the low velocities in this area. However, the contribution of basal motion below $\sim 1700 \mathrm{~m}$ appears to be lower than that of the central region and is the most sensitive to uncertain model parameters.

The measured surface velocities between 1700 and $3300 \mathrm{~m}$ are higher than expected for a surge-type glacier

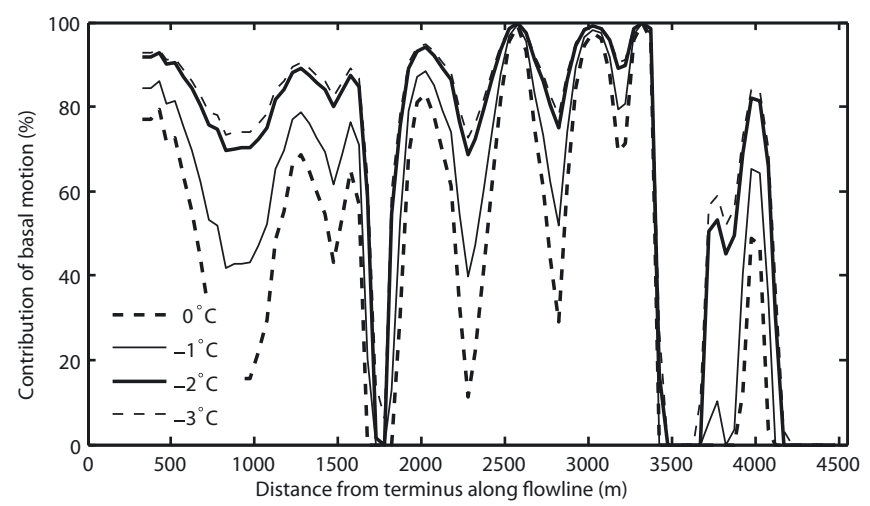

Fig. 12. Sensitivity test with a variable flow-law coefficient, $A$, for the 2007/08 annual dataset. The flow-law coefficient is expressed in terms of effective ice temperature. A value of $-2{ }^{\circ} \mathrm{C}$ was used in the control tests and inversion of real data. 


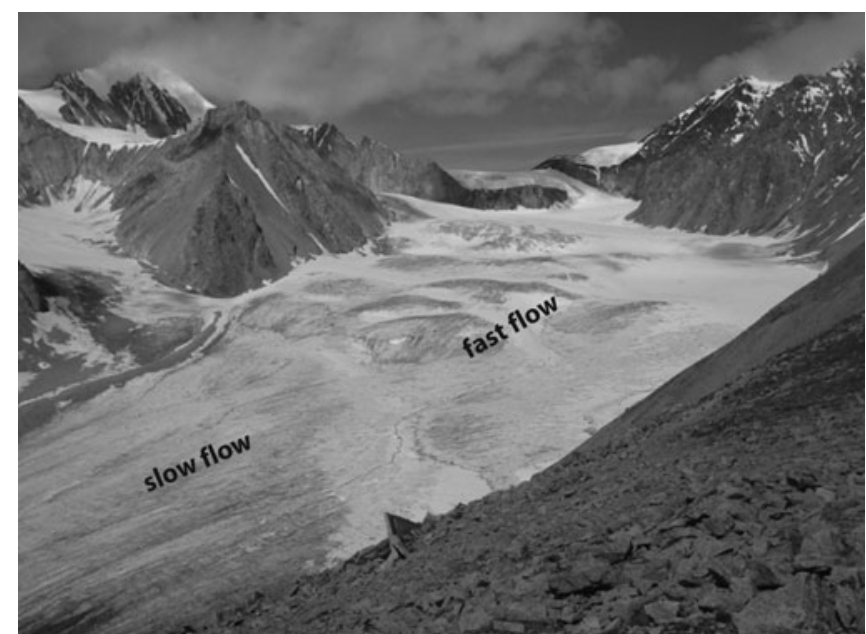

Fig. 13. Photograph of the study glacier in July 2007, showing the transition between the faster-flowing ice above (characterized by surface undulations $\sim 20-30 \mathrm{~m}$ high) and the slowly flowing ice below (C.G. Schoof). This transition marks what we interpret as the active ice front or surge 'bulge'.

of this size in its quiescent phase. For example, Frappé and Clarke (2007) report surface velocities of $\sim 8 \mathrm{~m} \mathrm{a}^{-1}$ in 2005 for Trapridge Glacier, which is similar in areal extent and thickness to the study glacier and located in the same region. High measured flow speeds in the central zone of the study glacier are accomplished primarily by basal motion, as determined by the inverse model and visually substantiated by the glacier surface morphology. Although the surface velocities appear to exhibit a seasonal cycle, the high contribution of basal motion over the central region of the glacier applies equally to annual and summer datasets.

Balance velocity calculations made with the current glacier geometry and a net surface mass-balance profile based on 2006/07 measurements show that the current flow regime is in a state of disequilibrium (De Paoli, 2009) and requires glacier thinning in order to be maintained. We do not have long-term mass-balance records for this glacier, but there is little evidence that mass balance has recently been close to zero or positive in this region, as would be required to sustain the current flow rates. Arendt and others (2002) calculate high rates of thinning $\left(>1.5 \mathrm{ma}^{-1}\right)$ for nearby Kaskawulsh Glacier for the period $\sim 1950$ 1995 , and somewhat lower rates of thinning $\left(\sim 0.5 \mathrm{~m} \mathrm{a}^{-1}\right)$ for the period $\sim 1995-2001$ from repeat airborne laser altimetry. Our 2007 net mass-balance estimates for the study glacier and another glacier in the Donjek Range (Wheler, 2009) are very similar to the negative 2003-07 net mass-balance estimates for the St Elias region derived from Gravity Recovery and Climate Experiment (GRACE) data (Luthcke and others, 2008) and from aircraft laser altimetry (Arendt and others, 2008). This leads us to conclude that the current dynamic regime is unlikely to be a remnant of some recent period of higher mass balance. Furthermore, calculation of ice flux along the flowline shows a distinct gradient across the transition at $\sim 1700 \mathrm{~m}$ with higher flux above and lower flux below (not shown) that cannot be explained by the surface mass balance. This is suggestive of a dynamically driven propagation of mass. Preliminary force-balance calculations, including longitudinal stresses, give no indication of the elevated flow speeds observed
Table 3. Values of effective ice temperatures and associated flowlaw coefficients (Paterson, 1994, p. 97) used in the sensitivity test. $A=2.4 \times 10^{-24} \mathrm{~Pa}^{-3} \mathrm{~s}^{-1}$ was used in the control tests and inversion of real data
Temperature

${ }^{\circ} \mathrm{C}$

0

$-1$

$-2$

$-3$
Flow-law coefficient, $A$

$$
\mathrm{Pa}^{-3} \mathrm{~s}^{-1}
$$

over the central region of the glacier flowline (personal communication from N. Roux, 2009), which argues against the current flow regime being simply a product of glacier geometry.

Based on the evidence above, we suggest that the glacier is undergoing a 'slow surge', as described for Trapridge Glacier by Frappé and Clarke (2007). The active phase of the Trapridge Glacier surge lasted 20 years and was characterized by peak velocities of $\sim 40 \mathrm{~m} \mathrm{a}^{-1}$ in the central region of the glacier; these velocities were attributed primarily to basal motion (Frappé and Clarke, 2007). The active ice was not particularly heavily crevassed but did form a bulge that was ultimately coincident with the glacier margin. Although Trapridge Glacier had undergone a dramatic surge some time before 1951, its most recent surge was too slow to be attended by many of the obvious surge diagnostics, such as lateral shear margins and extensive chaotic crevassing. The description of Frappé and Clarke (2007) bears a striking similarity to our observations on the study glacier, with the dynamic and morphological transition at $\sim 1700 \mathrm{~m}$ marking the active ice front or surge 'bulge' (Fig. 13). It is unclear whether the region above $\sim 3300 \mathrm{~m}$ is actively involved in the surge. Photographs of the two previous surges make it difficult to determine the extent to which the upper basin has participated in these surges. If the comparison with Trapridge Glacier holds, we might expect the upper basin to undergo a subdued flow acceleration compared to the central glacier (Frappé and Clarke, 2007).

The study glacier surged around 1951 (Fig. 2) and again in 1986-87. Other available imagery, from the early 1970 s to the early 1980s, shows no signs of surge behaviour or recent recovery from a surge. Unless the glacier surged again after 1951 but well before the early 1970s, the observations above suggest a surge period of 30-40 years, a value within the range established by Meier and Post (1969) for surge-type glaciers in the St Elias Mountains. If, as Frappé and Clarke (2007) suggest, the long slow phase of a surge may simply be a preamble to the shorter faster phase, perhaps the current behaviour of the study glacier is part of the natural surge cycle. If the natural surge cycle does not include these two phases, then the current surge is much weaker than the previous two and may have occurred prematurely. If this is the case, it seems plausible that the glacier has been unable to accumulate sufficient mass to support a vigorous surge. If changes in glacier mass balance are having a significant effect on the nature of glacier surges, this challenges the traditional notion of surges being independent of climate and may lead us to reconsider this relationship (e.g. Hewitt, 2007). 


\section{CONCLUSION}

We measured surface velocities along an approximate flowline of a small surge-type glacier in Yukon from 2006 to 2008. Three zones are identified along the flowline, based on the velocity structure and observed surface morphology of the glacier: (1) lower $1700 \mathrm{~m}$ : slowly flowing crevasse-free ice; (2) 1700-3300 m: ice with the highest velocities (20$\left.35 \mathrm{~m} \mathrm{a}^{-1}\right)$, pronounced surface undulations and significant crevassing; and (3) distances greater than $3300 \mathrm{~m}$ : ice with moderate velocities, surface topography and crevassing. While these velocities are much lower than typical surge velocities reported for small surge-type glaciers in the St Elias Mountains, the velocities in the central zone of the glacier are comparable to those measured on Trapridge Glacier during its recently reported 'slow surge' (Frappé and Clarke, 2007).

We used geophysical inversion methods to infer basal velocity profiles from the surface velocities described above. Sliding or bed deformation is responsible for $\sim 50-100 \%$ of the total glacier motion over much of the flowline, with the contribution of basal motion being particularly high over the central region of the glacier. This flow regime characterizes both the 'summer' and annual mean datasets, demonstrating a significant role for basal motion year-round. Calculations of ice flux reveal a strong gradient at $\sim 1700 \mathrm{~m}$, indicative of dynamically driven propagation of mass from the fast-flowing central region to the nearly stagnant lower region of the glacier. Balance velocity calculations show the glacier to be out of equilibrium with recent mass balance, with glacier thinning required to sustain the current flow regime.

Based on what we know of its surge history, and what this study has revealed about its current dynamics, we suggest that the study glacier may currently be undergoing a 'slow surge' as described by Frappé and Clarke (2007). Whether this behaviour represents a climatically driven departure from the glacier's previous surge behaviour is unknown at this time. In either case, the dynamics of this glacier are driving changes in glacier morphology that may have implications for its future mass balance. This study provides a starting point for investigating the mutual influence of surge-type glacier dynamics and mass balance at a wider scale.

\section{ACKNOWLEDGEMENTS}

We are grateful to the Natural Sciences and Engineering Research Council of Canada (NSERC), the Canada Foundation for Innovation (CFI), the Canada Research Chairs (CRC) Program and Simon Fraser University for funding. Permission to conduct this research was granted by the Kluane First Nation, Parks Canada, and the Yukon Territorial Government. Support from the Kluane Lake Research Station (KLRS) and Kluane National Park and Reserve is greatly appreciated. We are indebted to A. Williams, S. Williams, L. Goodwin (KLRS) and D. Makkonen (Trans North Helicopters) for logistical support, and to B. Wheler, J. Logher, C. Doughty, P. Belliveau and A. Jarosch for field assistance. We thank Whistler-Blackcomb for facilitating the testing of our radar system. Finally, we are grateful to M. Truffer, $\mathrm{H}$. Pritchard and C. Martin for their thoughtful comments on the manuscript, and to H.A. Fricker, our Scientific Editor.

\section{REFERENCES}

Arendt, A.A., K.A. Echelmeyer, W.D. Harrison, C.S. Lingle and V.B. Valentine. 2002. Rapid wastage of Alaska glaciers and their contribution to rising sea level. Science, 297(5580), 382-386.

Arendt, A.A., S.B. Luthcke, C.F. Larsen, W. Abdalati, W.B. Krabill and M.J. Beedle. 2008. Validation of high-resolution GRACE mascon estimates of glacier mass changes in the St Elias Mountains, Alaska, USA, using aircraft laser altimetry. J. Glaciol., 54(188), 778-787.

Clarke, G.K.C., S.G. Collins and D.E. Thompson. 1984. Flow, thermal structure, and subglacial conditions of a surge-type glacier. Can. J. Earth Sci., 21(2), 232-240.

Constable, S.C., R.L. Parker and C.G. Constable. 1987. Occam's inversion: a practical algorithm for generating smooth models from electromagnetic sounding data. Geophysics, 52(3), 289-300.

De Paoli, L. 2009. Dynamics of a small surge-type glacier, St. Elias Mountains, Yukon Territory, Canada: characterization of basal motion using 1-D geophysical inversion. (MSc thesis, Simon Fraser University.)

Eisen, O. 2008. Inference of velocity pattern from isochronous layers in firn, using an inverse method. J. Glaciol., 54(187), 613-630.

Flowers, G.E. and G.K.C. Clarke. 1999. Surface and bed topography of Trapridge Glacier, Yukon Territory, Canada: digital elevation models and derived hydraulic geometry. J. Glaciol., 45(149), 165-174.

Frappé, T.-P. and G.K.C. Clarke. 2007. Slow surge of Trapridge Glacier, Yukon Territory, Canada. J. Geophys. Res., 112(F3), F03S32. (10.1029/2006JF000607.)

Glen, J.W. 1955. The creep of polycrystalline ice. Proc. R. Soc. London, Ser. A, 228(1175), 519-538.

Gudmundsson, G.H., G. Aðalgeirsdóttir and H. Björnsson, 2003. Observational verification of predicted increase in bedrock-tosurface amplitude transfer during a glacier surge. Ann. Glaciol., 36, 91-96.

Hewitt, K. 2007. Tributary glacier surges: an exceptional concentration at Panmah Glacier, Karakoram Himalaya. J. Glaciol., 53(181), 181-188.

Johnson, P.G. 1997. Spatial and temporal variability of ice-dammed lake sediments in alpine environments. Quat. Sci. Rev., 16(7), 635-647.

Johnson, P.G. and J.N. Kasper. 1992. The development of an icedammed lake: the contemporary and older sedimentary record. Arct. Alp. Res., 24(4), 304-313.

Kamb, B. and K.A. Echelmeyer. 1986. Stress-gradient coupling in glacier flow: I. Longitudinal averaging of the influence of ice thickness and surface slope. J. Glaciol., 32(111), 267-284.

Kamb, B. and 7 others. 1985. Glacier surge mechanism: 19821983 surge of Variegated Glacier, Alaska. Science, 227(4686), 469-479.

Kasper, J.N. 1989. An ice-dammed lake in the St. Elias Range, southwestern Yukon Territory: water balance, physical limnology, ice dynamics and sedimentary processes. (MA thesis, University of Ottawa.)

Luthcke, S.B., A.A. Arendt, D.D. Rowlands, J.J. McCarthy and C.F. Larsen. 2008. Recent glacier mass changes in the Gulf of Alaska region from GRACE mascon solutions. J. Glaciol., 54(188), 767-777.

Meier, M.F. and A. Post. 1969. What are glacier surges? Can. J. Earth Sci., 6(4), 807-817.

Murray, T., T. Strozzi, A. Luckman, H. Jiskoot and P. Christakos. 2003. Is there a single surge mechanism? Contrasts in dynamics between glacier surges in Svalbard and other regions. J. Geophys. Res., 108(B5), 2237. (10.1029/2002JB001906.)

Narod, B.B. and G.K.C. Clarke. 1994. Miniature high-power impluse trnasmitter for radio-echo sounding. J. Glaciol., 40(134), 190-194.

Nye, J.F. 1952. The mechanics of glacier flow. J. Glaciol., 2(12), 82-93. 
Nye, J.F. 1965. The flow of a glacier in a channel of rectangular, elliptic or parabolic cross-section. J. Glaciol., 5(41), 661-690.

Parker, R.L. 1994. Geophysical inverse theory.. Princeton, NJ, Princeton University Press.

Paterson, W.S.B. 1994. The physics of glaciers. Third edition. Oxford, etc., Elsevier.

Taylor, J.R. 1982. An introduction to error analysis. Oxford, Oxford University Press.

Truffer, M. 2004. The basal speed of valley glaciers: an inverse approach. J. Glaciol., 50(169), 236-242.

Waddington, E.D., T.A. Neumann, M.R. Koutnik, H.-P. Marshall and D.L. Morse. 2007. Inference of accumulation-rate patterns from deep layers in glaciers and ice sheets. J. Glaciol., 53(183), 694-712.

Wheler, B.A. 2009. Glacier melt modelling in the Donjek Range, St. Elias Mountains, Yukon Territory. (MSc thesis, Simon Fraser University.)

\section{APPENDIX: DETERMINATION OF THE FLOW-LAW COEFFICIENT, $\boldsymbol{A}$}

In order to constrain the flow-law coefficient, we use a simple one-dimensional model to calculate plausible vertical temperature profiles within the ice. These temperatures are weighted according to a hypothetical strain-rate profile, to calculate an effective ice temperature that can be used to guide our choice of $A$ according to Paterson (1994, p. 97). A detailed methodology and description of the results are given by De Paoli (2009). The temperature distribution with depth, $z$, and time, $t$, can be described by the following partial differential equation:

$$
\frac{\partial T}{\partial t}=\frac{1}{\rho C(T)}\left[K(T) \frac{\partial^{2} T}{\partial z^{2}}+\frac{\partial K(T)}{\partial T}\left(\frac{\partial T}{\partial z}\right)^{2}+\Phi\right],
$$

where $\rho$ is the ice density, $C(T)=7.7929 T-$ $13.331 \mathrm{~J} \mathrm{~kg}^{-1} \mathrm{~K}^{-1}$ is the heat capacity, $K(T)=9.085 \times$ $10^{-5} T^{2}-0.053 T+10.4204 \mathrm{~W} \mathrm{~m}^{-1} \mathrm{~K}^{-1}$ is the thermal conductivity and $\Phi=2 A_{0} \exp (-Q / R T)[\rho g(h-z) \sin \theta]^{n+1}$ is the strain heating with the temperature-independent component of the flow-law coefficient, $A_{0}=8.75 \times$ $10^{-13} \mathrm{~Pa}^{-3} \mathrm{~s}^{-1}$ (Paterson, 1994, p. 97), the creep activation energy for ice $Q=6.07 \times 10^{4} \mathrm{~J} \mathrm{~mol}^{-1}$, the ideal gas constant $R=8.314 \mathrm{~J} \mathrm{~mol}^{-1} \mathrm{~K}^{-1}$, the acceleration due to gravity $\mathrm{g}=9.81 \mathrm{~m} \mathrm{~s}^{-2}$ and Glen's flow-law exponent $n=3$. We solve this equation numerically at $\Delta z=1 \mathrm{~m}$ intervals for a slab of thickness $h=78 \mathrm{~m}$ and slope of $\theta=10.1^{\circ}$, the respective means of ice thickness and surface slope for the study glacier. The boundary condition at the surface is derived from year-round measurements of $2 \mathrm{~m}$ air temperature near stake $\mathrm{S} 6$
Table 4. Boundary conditions used in the temperature model

Name Value

Surface boundary condition: constant temperature

Mean annual temperature $-8.6^{\circ} \mathrm{C}$

Surface boundary condition: varying temperature Mean winter temperature $-14.8^{\circ} \mathrm{C}$

Mean spring temperature

Mean summer temperature

Mean autumn temperature

Basal boundary condition

Fixed temperature (Dirichlet)

$0^{\circ} \mathrm{C}$

Fixed geothermal flux (Neumann) $0.07 \mathrm{~W} \mathrm{~m}^{-2}$

(Fig. 1). We experiment with both constant and varying surface temperatures, as well as with Neumann (fixed heat flux) and Dirichlet (fixed temperature) boundary conditions at the glacier bed. Values for both surface and bed boundary conditions are presented in Table 4. Simulations are initialized with a linear temperature profile and run to steady state before a varying surface boundary condition is imposed. In the simulations with a Dirichlet boundary condition at the bed, ice temperatures reach a minimum between -6 and $-8^{\circ} \mathrm{C}$ below the surface layer affected by the annual temperature wave. Neumann boundary conditions at the bed result in basal temperatures between -6 and $-7^{\circ} \mathrm{C}$.

To calculate an effective ice temperature from these hypothetical temperature profiles, we vertically integrate the temperature weighted by a normalized strain rate. The strain rate is calculated for a slab glacier as

$$
\dot{\epsilon}=A_{0} \exp \left(-\frac{Q}{R T}\right)(\rho \mathrm{g} z \sin \theta)^{n} .
$$

The result is an effective ice temperature of -1.7 to $-1.9^{\circ} \mathrm{C}$ for a temperate glacier bed, and -6.4 to $-7.0^{\circ} \mathrm{C}$ for a frozen bed. From preliminary measurements of ice temperature in 2008, and the glacier behaviour inferred from our measurements and modelling, we posit that the glacier bed is at the melting point over most of the flowline. We have therefore adopted a reference value for the effective temperature of $-2^{\circ} \mathrm{C}$, and a flow-law coefficient of $A=$ $2.4 \times 10^{-24} \mathrm{~Pa}^{-3} \mathrm{~s}^{-1}$ according to Paterson (1994, p. 97). This simple modelling exercise does not include the effect of glacier dynamics on temperature, beyond the strain-rate weighting. It is only performed for one glacier geometry and surface temperature forcing, and at one location along the glacier flowline. 